\title{
The influence of a column shape cross-section on the punching capacity
}

\author{
Simona Sarvaicova ${ }^{1}$, Viktor Borzovic ${ }^{2}$, Tomas Augustin ${ }^{3}$ \\ Faculty of Civil Engineering, Slovak University of Technology, Bratislava, Slovakia \\ E-mail: 1simona.sarvaicova@stuba.sk (corresponding author)
}

\begin{abstract}
The article deals with non-linear modeling of slab-column connection which represents a fragment of flat slab supported by a column and loaded up to the punching shear failure. The aim of this parametrical study is the analysis of the length of reduced control perimeters in the case of columns with significantly elongated rectangular cross-section. The non-linear analysis was performed in program Atena and calibrated by test results obtained from the laboratory experiments carried out at Slovak University of Technology in Bratislava. The results of non-linear analysis are compared with the values of shear resistance calculated according to the current Eurocode 2 model; fib Model Code 2010 and model proposed for the second generation of Eurocode 2 based on the Critical shear crack theory. The reliability of the models is evaluated by comparison of the results of numerical analyses and previously mentioned design models.
\end{abstract}

Keywords: flat slab, punching, shear capacity, non-linear modeling.

\section{Introduction}

Currently, flat slabs are widely used structures in practice. Columns with elongated rectangular cross-section are commonly used for instance in parking houses, so that the spans stay clear or in the buildings, where columns are aligned with partition walls. Punching shear around these columns is often the decisive criterion for ultimate limit state while designing the slab thickness and reinforcement.

This paper deals with internal columns which are centrically loaded. Shear stress of the flat slab in the basic control perimeter around columns with circle or square cross-section is characterized by a uniform distribution. Punching shear stress is different in the case of significantly elongated cross-section in one way. The main amount of the shear stress is concentrated near the column corners bases. In this case, the loading conditions also affects the bending moments distribution and the shear crack width opening which finally leads to shear failure.

The concentration of shear stress around rectangular columns was experimentally observed by several researchers (Moe, 1961; Hawkins, Falssen, \& Hinojosa, 1971), amongst others. Therefore, the determination of shear resistance is derived from reducing control perimeter to its effective lenght.

According to Eurocode 2 (EC2) and Model Code 2010 (MC2010), the reduced basic control perimeter is specified in the Figure 1. It is reduced to a length of $1.5 \mathrm{~d}$ from the corner along the longer side of the column cmax. The aim of this paper is a numerical non-linear analysis of punching resistance around a rectangular column with evaluation of the reliability of a simplified criterion for determining a reduced control perimeter.

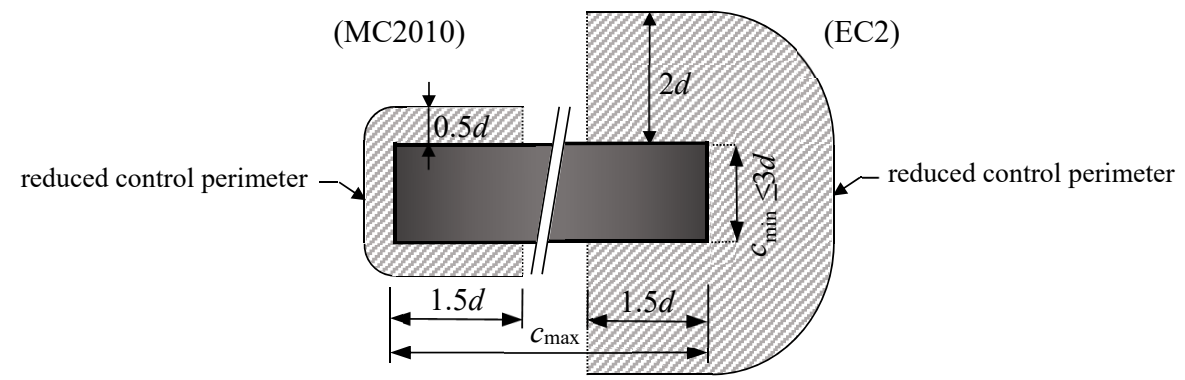

Figure 1. Reduced control perimeter according to design models EC2 and MC2010

(C) 2019 Authors. Published by VGTU Press. This is an open-access article distributed under the terms of the Creative Commons Attribution (http://creativecommons.org/licenses/by/4.0/) License, which permits unrestricted use, distribution, and reproduction in any medium, provided the original author and source are credited. 


\section{Design models}

Eurocode 2

The shear resistance in flat slabs without shear reinforcement is ensured by several aspects. It mainly depends on the aggregate interlock in shear crack, compressed concrete area under neutral axis and longitudinal reinforcement. These facts are considered in the empiric formula which determines the punching shear resistance of a slab according to EC2.

$$
V_{R d, c}=\frac{C_{R k, c}}{\gamma_{C}} k\left(100 \rho_{l} f_{c k}\right)^{1 / 3} u_{1} d
$$

where: $C_{R k, c}-$ empirical factor $[\mathrm{MPa}] ; \gamma_{C}-$ partial safety factor, $\gamma_{\mathrm{C}}=1.5[-] ; k-$ the size factor, $k=1+(200[\mathrm{~mm}] / d)^{0.5}$ $\leq 2.0[-] ; \rho_{l}-$ reinforcement ratio, $\rho=\left(\rho_{x} \rho_{y}\right)^{0.5}[-] ; f_{c k}-$ characteristic concrete compressive cylinder strength [MPa]; $u_{1}$ - shear-resisting basic control perimeter at distance of $2 d$ from the face of a column [mm]; $d$ - effective depth [mm].

\section{Model Code 2010}

Model Code 2010 is based on the Critical shear crack theory (Sagaseta, Tassinari, Fernández Ruiz, \& Muttoni, 2014). The shear resistance which depends on the crack widths is proportional to the slab rotation $\psi$. However, the load rotation is significantly non-linear. This fact was investigated with the result of a quadrilinear moment-curvature diagram which has been simplified for the design application. There are four levels of approximation of rotation calculation around the supported area. For this analysis the Level III of Approximation was used. The values of $r_{\mathrm{s}}$ and $m_{E d}$ were calculated from a linear elastic model.

$$
\begin{gathered}
V_{R d, c}=k_{\psi} \frac{\sqrt{f_{c k}}}{\gamma_{c}} b_{0} d_{v} ; \\
k_{\psi}=\frac{1}{1.5+0.9 k_{d g} \psi d} \leq 0.6,
\end{gathered}
$$

where: $k_{\phi}$ - parameter considering rotations of the slab [-]; $b_{0}$ - shear-resisting control perimeter at distance of $0.5 d$ from the face of a column [mm]; $d_{v}$ - shear-resisting effective depth [mm]; $k_{d g}$-parameter considering the maximum aggregate size, $k_{d g}=\frac{32}{16+d_{\mathrm{g}}} \geq 0.75 \quad[-] ; d_{g}-$ maximum aggregate size $[\mathrm{mm}] ; \quad \psi-$ slab rotation [-].

$$
\psi=1.2 \frac{r_{s}}{d} \frac{f_{y m}}{E_{s}}\left(\frac{m_{E d}}{m_{R d}}\right)^{1.5}
$$

where: $r_{s}$ - the distance from the column's axis to the line of the contraflexure of the radial bending moments [m]; $f_{y m}-$ yield strength of the main reinforcement [MPa]; $m_{E d}$ - average design bending moment per unit of length $[\mathrm{kNm} / \mathrm{m}]$; $m_{R d}$ - average design bending capacity of a slab per unit of length $[\mathrm{kNm} / \mathrm{m}]$.

\section{prEurocode 2}

This model is also based on the Critical shear crack theory, but the expression of equation is closer to EC2 (2004). The mechanical model of the CSCT considers that crack localization occurs in a single crack (named as critical shear crack), and that the capacity of the critical shear crack to transfer shear forces depends upon the displacements between crack lips and their roughness (Muttoni, Fernández Ruiz, \& Simões, 2017). More details about this design model are available to see in CEN TC250/SC2.

$$
\begin{gathered}
V_{R d, c}=\frac{0.6}{\gamma_{C}} k_{p b}\left(100 * \rho f_{c k} \frac{d_{d g}}{\sqrt{d_{v} \frac{r_{s}}{8}}}\right)^{1 / 3} b_{0} d_{v} \\
k_{p b}=\sqrt{5 . \mu_{p} \frac{d_{v}}{b_{0}}}<2.5
\end{gathered}
$$

where: $d_{d g}-$ a size parameter which describes the failure zone roughness considering the concrete class and aggregate properties; $d_{d g}=16 \mathrm{~mm}+d_{g, \max } \leq 40 \mathrm{~mm}$ if $f_{\mathrm{ck}} \leq 60 \mathrm{MPa}[\mathrm{mm}] ; \mu_{\mathrm{p}}-$ a coefficient accounting for the shear force gradient and bending moments in the region of the control perimeter, for internal column: $\mu_{p}=8 / k_{e}[-] ; k_{e}-\mathrm{a}$ factor 
considering an influence of reduced control perimeter, $k_{e}=b_{0} / b_{0, \text { red }}[-] ; b_{0, \text { red }}$ - reduced control perimeter due to significantly elongated cross-section of a column [mm].

\section{The reduction of basic control perimeter - linear analysis}

The reduction of basic control perimeter for rectangular columns is based on the principle of shear force concentration which can be analyzed by finite element method using $2 \mathrm{D}$ elements. The column is modeled as a flat support with rigid springs transferring only compression. The concentration of shear stress along control perimeter is shown in Figure 2 , where the curves represent the flow of the nominal shear forces according to the loading conditions. The other option of displaying shear forces concentration is by observation of contact pressure in the column support (Sagaseta et al., 2014).

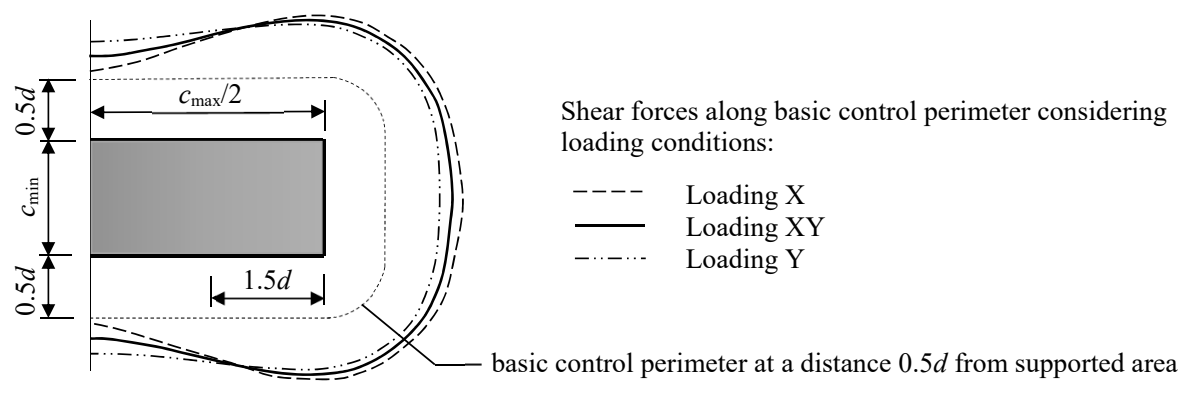

Figure 2. The distribution of shear forces along the basic control perimeter

\section{Non-linear analysis (NLA)}

\section{Test specimens}

Together seven slabs with thickness of $0.2 \mathrm{~m}$ are the subject of this analysis and they were all modelled in Atena, program based on non-linear finite element method. Test specimen represents planned experimental laboratory campaign. All of them were supported on internal column with rectangular cross-section. The first flat slab was supported by column with square cross-section dimension of $0.15 \times 0.15 \mathrm{~m}$, that means ratio $c_{\max } / c_{\min }=1$. The next specimens were modeled with increasing $c_{\max } / c_{\min }$ ratio with different values of $c_{\max }$ beginning at $0.15 \mathrm{~m}\left(=c_{\min }\right)$ up to $1.05 \mathrm{~m}$ $\left(7 \times c_{\min }\right)$. All slab specimens had the same dimensions $(2.5 \times 2.5 \mathrm{~m})$. The same reinforcement $\left(\rho_{1}=1.26 \%\right)$ using bars with $16 \mathrm{~mm}$ diameter spaced evenly by $100 \mathrm{~mm}$ in both directions were assumed for all specimens. All of them were designed without transverse reinforcement. Also, the nominal effective depth $(d)$ was $159 \mathrm{~mm}$, the same for each slab. The compression bottom face of slab was reinforced with $10 \mathrm{~mm}$ bars evenly spaced by $200 \mathrm{~mm}$.

a) Loading $\mathrm{XY}$

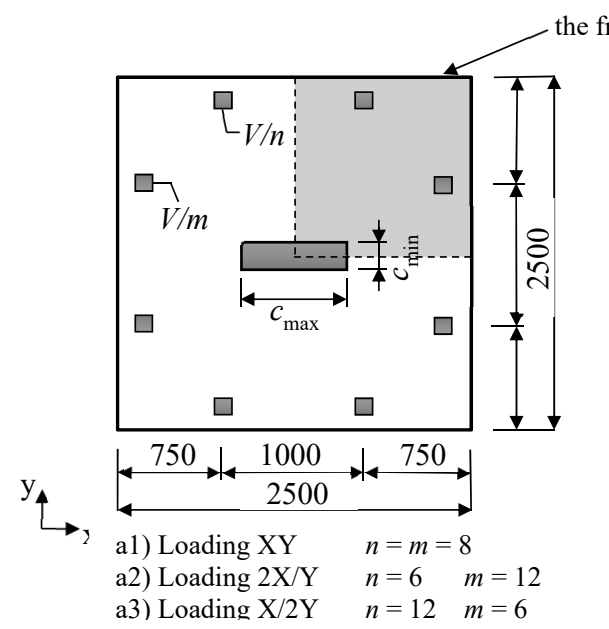

b) Loading $X$

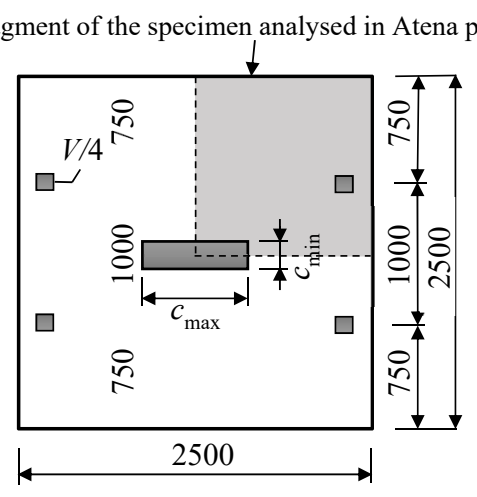

$V-$ total shear force $[\mathrm{kN}]$ c) Loading $Y$

Figure 3. Loading conditions: a) loading along the whole specimen; b) loading in the direction parallel to $c_{\max }$;

c) loading in the direction parallel to $c_{\text {min }}$ 


\section{Material properties}

For non-linear analysis the following material properties were assumed. Concrete cylinder strength $f_{c m}$ was considered $33 \mathrm{MPa}$. The maximum aggregate size $d_{g \text {,max }}$ was assumed $16 \mathrm{~mm}$. Steel used as reinforcement had yield strength of $f_{y m}=550 \mathrm{MPa}$.

\section{Loading conditions}

Five various loading conditions were analysed for each specimen. They represent different length of adjacent span in X and Y direction. The first one (Loading XY) represents concentric loading uniformly distributed around the column. Together eight equivalent forces were used for the whole specimen as it is shown in Figure 3a1. The next two types (Loading $2 \mathrm{X} / \mathrm{Y}$, Loading $\mathrm{X} / 2 \mathrm{Y}$ ) represent prevailing loading from $\mathrm{X}$-axis or $\mathrm{Y}$-axis direction. The last two loading conditions (Loading X, Loading Y) represent almost one-way spanning (Figure $3 b, c)$. There were used four forces applied by two pairs on the opposite sides of specimens.

\section{Calibration of the non-linear models}

The fracture-mechanics parameters of the numerical model are based on work (Kadlec \& Cervenka, 2015) and (Augustin, Fillo, Halvonik, \& Marčiš, 2018). The five finite elements on the thickness of the slab were chosen, because no changes in the trend (5-10 elements) of the load-deflection curve or the ultimate resistance were noticed (Kadlec \& Cervenka, 2015) and (Augustin et al., 2018). Also the combination of tetra and brick elements is not recommended, leading to the underes-timation of the ultimate resistance. For this case the extrusion of the brick elements seems to be reasonable.

For the fixed crack model coefficient (where 0 - fully rotated crack, 1 - fully fixed crack) using " 0 ", lower value of the ultimate resistance and unrealistic shear crack inclination is obtained (Figure 4). Therefore because of a good match with the experiment, fixed crack was used in the analysis.
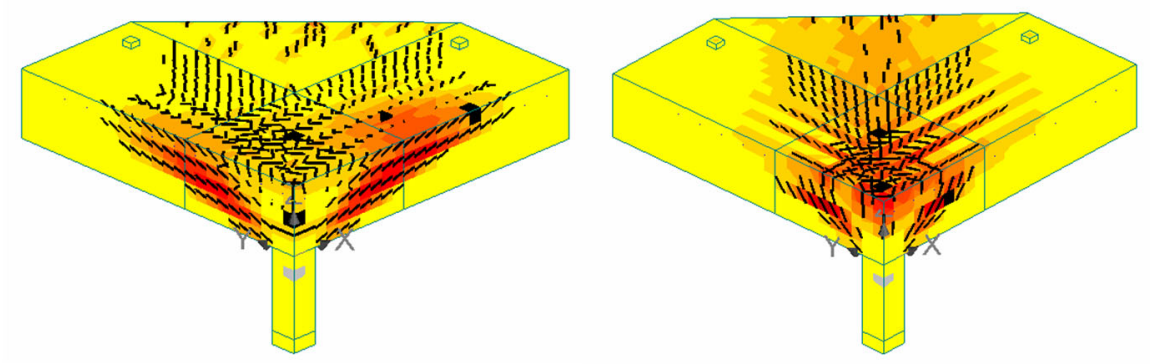

Figure 4. Fully rotated crack (left), fully fixed crack (right)

Atena (V. Červenka, Jendele, \& J. Červenka, 2018), MC1990 and MC 2010 have a small difference in concrete tensile strength $(10 \%)$. However, the difference in fracture energy is significant. This difference is justified in (fib Bulletin 70, 2013) and refers to a better match with experiments (Figure 5). Based on these experiments, the MC1990 significantly underestimates the fracture energy for all concrete strengths up to $110 \mathrm{MPa}$. However, Atena FEM software is based on MC1990 and using the fracture energy leads to good match with experiments (Figure 5, difference only $12 \%$ ). The fracture energy model introduced in MC2010 is not recommended to be used in Atena because it leads to the ultimate resistance overestimation.

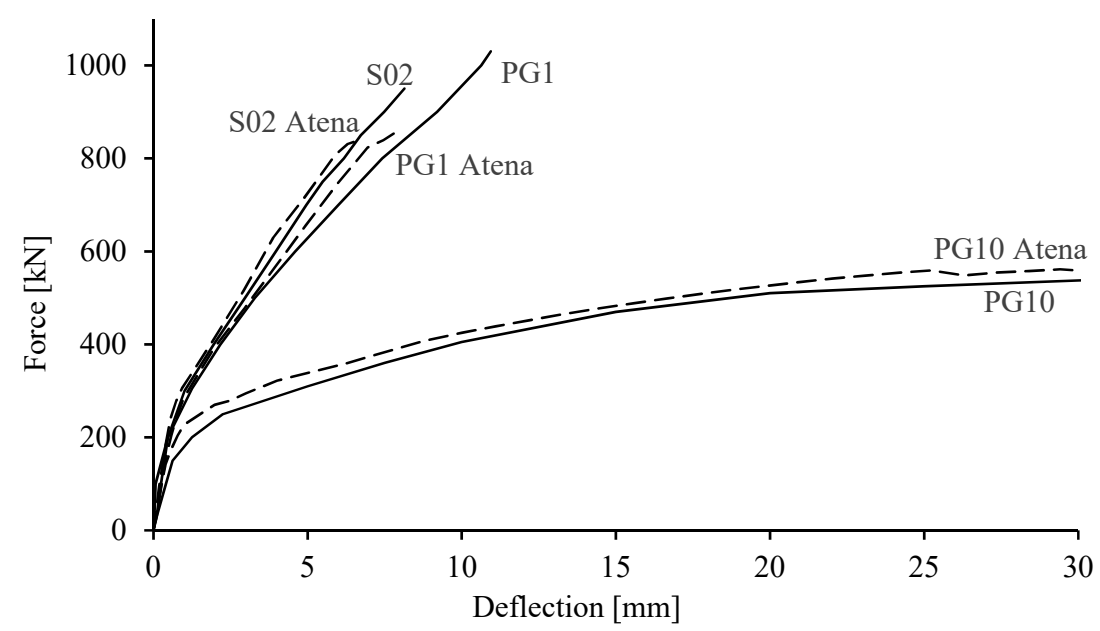

Figure 5. Load-deflection relation S02 (Augustin et al., 2018), PG1 PG10 (Guandalini, Burdet, \& Muttoni, 2009) 


\section{Test results}

Figure 6 shows specimen deflections with cracks pattern one step before failure. All three specimens are uniformly loaded (Loading XY), each supported by column with various $c_{\max }$ dimension. In all cases the main shear crack can be observed and the specimen's failure can be confirmed by exceeding the punching shear capacity. Figure 7 represents the influence of the loading conditions for the specimen supported on column with the ratio $c_{\max } / c_{\min }=3$.
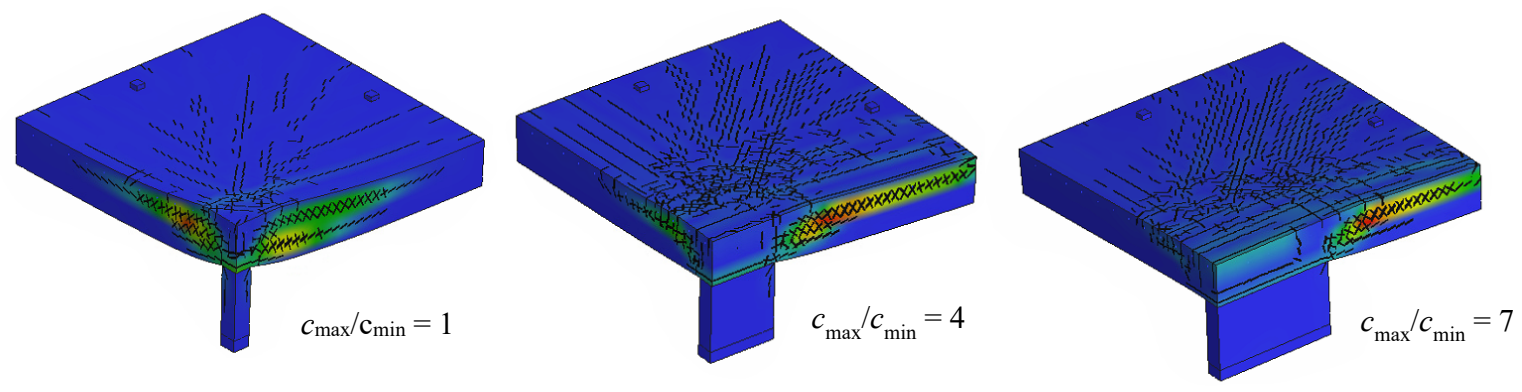

Figure 6. Deflection and crack pattern before specimen's failure for various $\mathrm{c}_{\max } / \mathrm{c}_{\min }$ ratio

Table 1 summarizes the shear resistances calculated by previously mentioned design models. For specimens supported by column with $c_{\max }>3 d$, shear resistances were evaluated by considering both full and reduced control perimeter. The last column in the table shows the values from the non-linear analysis calculated by Atena program.

According to this parametrical study, the EC2 design model is the closest to the results obtained from non-linear analysis while considering uniform loading (Loading XY). The influence of the reduction of control perimeter on the shear resistance is obvious mainly in the case of loading condition Loading X (Figure 9). This loading condition represent dominant span length in X-direction. Punching shear resistance significantly decreased and its value is closer to the EC2 model considering reduced control perimeter.

Assuming that punching shear resistances obtained from NLA are closest to the actual behavior, it can be concluded that punching shear resistances evaluated by each design model are all on the safe side. Ratio between Atena results and punching shear resistances $\left(\mathrm{V}_{\mathrm{ATENA}} / \mathrm{V}_{\mathrm{R}, \mathrm{c}}\right)$ get range 1.01-1.06 for EC2 model, 1.08-1.18 for prEC2 and 1.141.26 for MC2010, as it is shown in Figure 7b. Based on evaluation of shear resistance Model Code 2010 is the safest approach among the considered models.

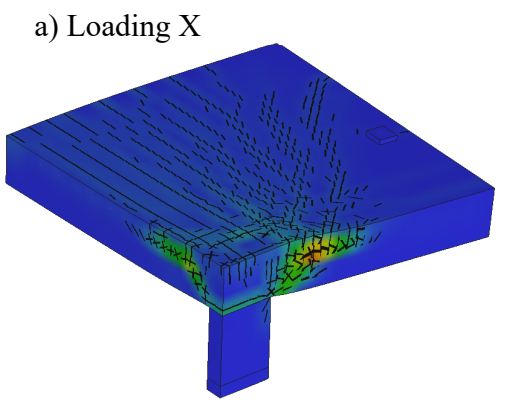

d) Loading $\mathrm{X} / 2 \mathrm{Y}$

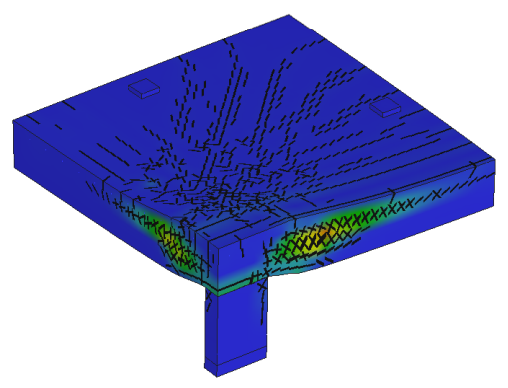

b) Loading $2 \mathrm{X} / \mathrm{Y}$

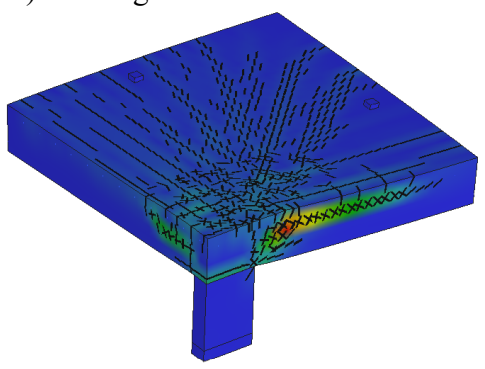

e) Loading Y

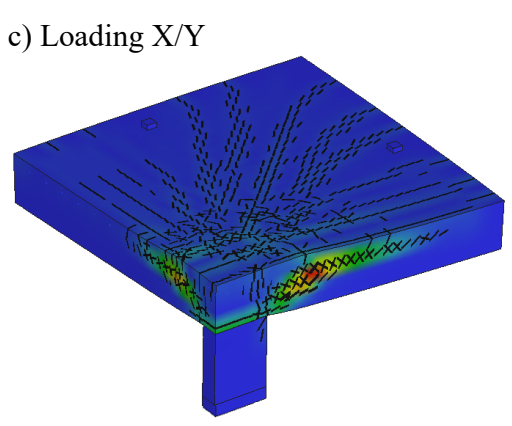

c) Loading $X / Y$

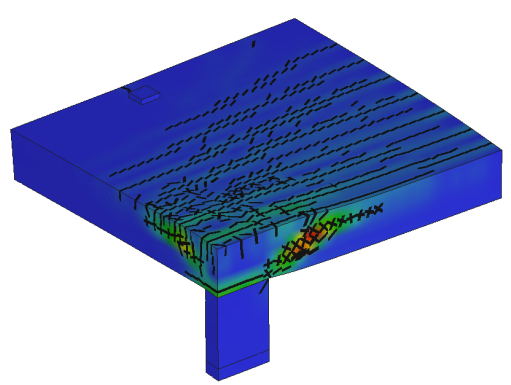

Figure 7. Deflection and crack pattern before specimen's failure for various loading conditions 
Sarvaicova, S.; Borzovic, V.; Augustin, T. 2019. The influence of a column shape cross-section on the punching capacity

Table 1. Comparison of punching shear resistance calculated by various design models to values from NLA

\begin{tabular}{|c|c|c|c|c|c|c|c|c|}
\hline \multirow{2}{*}{\multicolumn{2}{|c|}{$\begin{array}{l}\text { Cross-section } \\
\text { dimensions }\end{array}$}} & \multicolumn{6}{|c|}{ Design model } & \multirow{3}{*}{$\begin{array}{c}\begin{array}{l}\text { Non-linear } \\
\text { calculation }\end{array} \\
\text { Loading XY }\end{array}$} \\
\hline & & \multicolumn{2}{|c|}{ EC2 (2004) } & \multicolumn{2}{|c|}{ prEC2 (2018) } & \multicolumn{2}{|c|}{ MC2010 } & \\
\hline$c_{\text {min }}$ & $c_{\max }$ & full $u_{1}$ & reduced $u_{1}$ & full $b_{0}$ & reduced $b_{0}$ & full $b_{0}$ & reduced $b_{0}$ & \\
\hline \multicolumn{2}{|c|}{$[\mathrm{m}]$} & \multicolumn{6}{|c|}{$V_{\mathrm{R}, \mathrm{c}}[\mathrm{kN}]$} & $V_{\text {ATENA }}[\mathrm{kN}]$ \\
\hline \multirow{7}{*}{0.15} & 0.15 & 547 & - & 513 & - & 453 & - & 572 \\
\hline & 0.30 & 610 & - & 578 & - & 530 & - & 622 \\
\hline & 0.45 & 674 & - & 637 & - & 598 & - & 692 \\
\hline & 0.60 & 737 & \multirow{4}{*}{685} & 691 & \multirow{4}{*}{648} & 660 & \multirow{4}{*}{510} & 752 \\
\hline & 0.75 & 800 & & 742 & & 716 & & 822 \\
\hline & 0.90 & 863 & & 788 & & 768 & & 862 \\
\hline & 1.05 & 926 & & 833 & & 816 & & 982 \\
\hline
\end{tabular}

Table 2. Punching shear resistances obtained from NLA considering various loading conditions

\begin{tabular}{|c|c|c|c|c|c|c|}
\hline \multicolumn{2}{|c|}{ Cross-section dimensions [m] } & \multicolumn{5}{|c|}{ Punching shear resistance $\mathrm{V}_{\text {ATENA }}[\mathrm{kN}]$} \\
\hline $\mathrm{c}_{\min }$ & $\mathrm{c}_{\max }$ & $\begin{array}{c}\text { Loading } \\
\text { X }\end{array}$ & $\begin{array}{l}\text { Loading } \\
2 \mathrm{X} / \mathrm{Y}\end{array}$ & $\begin{array}{l}\text { Loading } \\
\text { XY }\end{array}$ & $\begin{array}{l}\text { Loading } \\
\mathrm{X} / 2 \mathrm{Y}\end{array}$ & Loading Y \\
\hline \multirow{7}{*}{0.15} & 0.15 & 536 & 561 & 572 & 566 & 532 \\
\hline & 0.30 & 662 & 632 & 622 & 632 & 592 \\
\hline & 0.45 & 712 & 682 & 692 & 682 & 662 \\
\hline & 0.60 & 742 & 782 & 752 & 762 & 732 \\
\hline & 0.75 & 732 & 772 & 822 & $812 *$ & $772^{*}$ \\
\hline & 0.90 & 732 & 782 & 872 & $902 *$ & $762^{*}$ \\
\hline & 1.05 & 742 & 783 & 982 & $923 *$ & $782 *$ \\
\hline \multicolumn{7}{|c|}{ Note: ${ }^{*}$ bending failure. } \\
\hline
\end{tabular}

a)

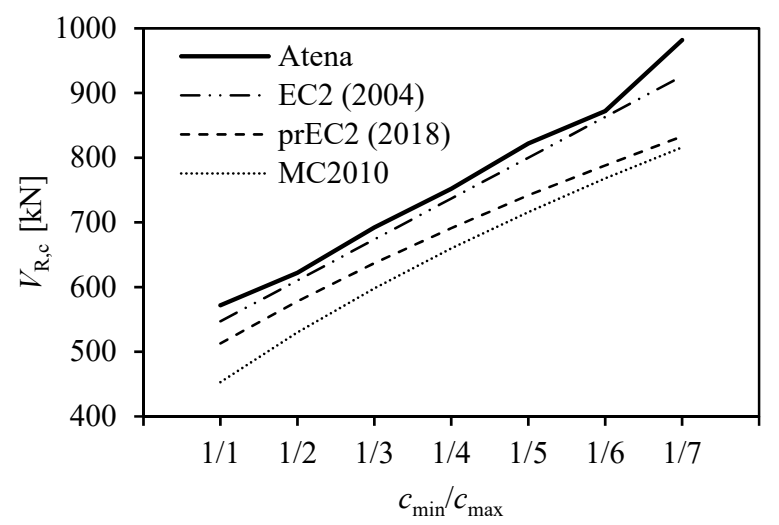

b)

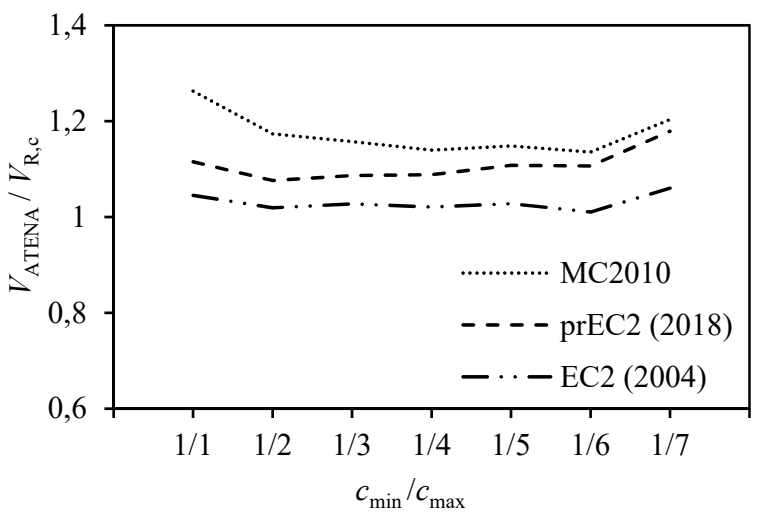

Figure 8. a) The influence of cross-section column dimensions on shear capacity calculated by different design models and non-linear calculation in Atena; b) the relation between $\mathrm{V}_{\mathrm{ATENA}} / \mathrm{V}_{\mathrm{R}, \mathrm{c}}$ for various design models

All specimens were subjected to five various types of loading conditions as it is presented in Figure 3 . The results have shown that shear capacity of uniformly loaded slab is comparable with the value of two-way loading condition where two thirds of the total load is located in $\mathrm{x}$-axis direction. Considering these two loading conditions, the value of shear capacity increases with enhancing $c_{\max }$.

The effect of the loading conditions on the shear resistance was investigated. It has been proven that column cross-section has also an impact on the type failure. While considering almost one-way loading in Y-direction (Loading $\mathrm{Y}$, Loading $\mathrm{X} / 2 \mathrm{Y}$ ), specimens with $\mathrm{c}_{\max } / \mathrm{c}_{\min } \leq 4$ failed by reaching punching shear capacity, while the others failed because the bending resistance was exceeded. The influence of loading conditions on punching shear capacity for different ration of $c_{\min } / c_{\max }$ is shown in Figure 9. 


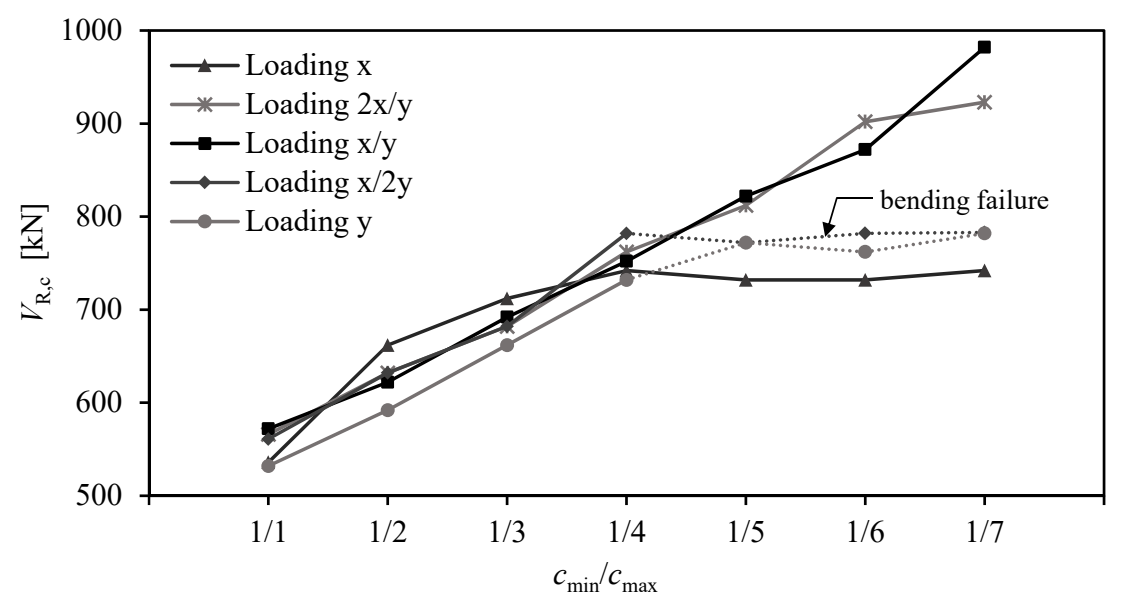

Figure 9. The influence of loading conditions on the punching shear capacity in non-linear analysis

\section{Conclucions}

This research deals with the influence of rectangular column cross-section on shear capacity. The individual column dimensions were in the range of $1 \leq c_{\max } / c_{\min } \leq 7$. The results from previous experiments (Augustin et al., 2018), (Guandalini et al., 2009) were used to calibrate the models in non-linear program Atena.

The results from non-linear analysis has shown, that loading conditions have significant influence on the type of failure, especially in the case of elongated rectangular columns. Linear analysis has proved the concentration of shear forces in the areas near column corners (Figure 2), resulting in the idea of reducing control perimeter. However, it was found out that slabs loaded in two-ways have similar punching shear resistance as the calculated value according to the EC2, while considering full control perimeter. This effect is caused by the redistribution of forces after cracks opening. Based on this analysis it is possible to refer the following statements:

1. In the case of non-linear analysis, the concentration of shear forces in the area near corners of the column with the dimension $c_{\max }>3 d$ is not significantly reflected as it is expected in the linear calculation. Based on the results from Atena, the reliability of individual models was evaluated. It has been proven that the evaluation of shear resistance by the design models (EC2, prEC2, MC2010) is on the safe side.

2. All analysed models represent internal slab-column connections. NLA has proved significant influence of loading conditions on punching shear capacity. This phenomenon is not possible to take into account for evaluation of shear resistance according to current EC2.

\section{Acknowledgements}

This work was supported by the Slovak Research and Development Agency under the contract No. APVV-15-0658 and Scientific Grant Agency of the Ministry of Education, science, research and sport of the Slovak Republic and the Slovak Academy of Sciences No 1/0240/19.

\section{References}

Augustin, T., Fillo, L., Halvonik, J., \& Marčiš, M. (2018, 22-23 November). Punching resistance of flat slabs with openings Experimental investigation. In Solid State Phenomena: $24^{\text {th }}$ Concrete Days 2017. Litomyšl, Czech Republic. https://doi.org/10.4028/www.scientific.net/SSP.272.41

Červenka, V., Jendele, L., \& Červenka, J. (2018). ATENA program documentation, Part 1, Theory. Prague: s.n.

European Commitee for Standardization. (2004). Eurocode 2: Design of concrete structures, Part 1-1: General rules and rules for buildings.

Fédération Internationale du Béton (fib). (2012). Bulletin n. 65/66 Model Code 2010. Final draft (vol. 1, 2. fib). Lausanne.

Fédération Internationale du Béton (fib). (2013). Bulletin 70 Code-type Models for Structural Behaviour of Concrete. Background of MC2010. Lausanne.

Guandalini, S., Burdet, O. L., \& Muttoni, A. (2009). Punching tests of slabs with low reinforcement ratios. ACI Structural Journal, 106(1), 87-95. https://doi.org/10.14359/56287

Hawkins, N. M., Falssen, H. B., \& Hinojosa, R. C. (1971). Influence of column rectangularity on the behaviour of flat plate structures. ACI Special Publication, SP-30(6), 127-146.

Kadlec, L., \& Cervenka, V. (2015, 18-20 May). Uncertainty of numerical models for punching resistance of rc slabs. In Concrete Innovation and Design, fib Symposium. Copenhagen, Denmark. 
Moe, J. (1961). Shearing strength of reinforced concrete slabs and footings under concentrate loads. Development Department. Bulletin D47. Portland Cement Association. 135 p.

Muttoni, A., Fernández Ruiz, M., \& Simões, J. T. (2017). The theoretical principles of the critical shear crack theory for punching shear failures and derivation of consistent closed-form design expressions. Structural Concrete, 19(1), 174-190. https://doi.org/10.1002/suco.201700088

Sagaseta, J., Tassinari, L., Fernández Ruiz, M., \& Muttoni, A. (2014). Punching of flat slabs supported on rectangular columns. Engineering Structures, 77, 17-33. https://doi.org/10.1016/j.engstruct.2014.07.007 